\title{
A escrita descentrada de Carolina Maria de Jesus
}

\author{
The decentering writing of Carolina Maria de Jesus \\ La escritura descentrada de Carolina Maria de Jesus \\ Luciana Paiva Coronel $\odot$ \\ Universidade Federal do Rio Grande, Rio Grande, RS, Brasil.
}

\begin{abstract}
RESUMO
Inserida no contexto da globalização, a ficção brasileira contemporânea recebe e processa os influxos da cultura desta etapa mais recente do capitalismo, na qual disseminam-se imagens padronizadas vinculadas à dinâmica do consumo e na qual, dialeticamente, emergem afirmações particularistas em relação a espaço, etnia ou gênero, entre outras marcas identitárias de alteridade. Carolina Maria de Jesus destaca-se nos primórdios desse cenário como autora em todos esses aspectos excêntrica, mas igualmente como produtora de uma escrita que escapa a quaisquer essencialismos, trazendo a marca do hibridismo. $\mathrm{O}$ artigo pretende analisar o descentramento que lhe é peculiar como decorrente de um processo de criação conceituado por Raffaella Fernandez (2015) como "poética de resíduos", que consiste em uma mescla de estilos literários desterritorializados, muitas vezes em atrito e sem síntese possível no interior de Quarto de despejo: diário de uma favelada.
\end{abstract}

Palavras-chave: Descentramento. Hibridismo. Poética de resíduos. Quarto de despejo.

\begin{abstract}
Inserted in the context of globalization, the contemporary Brazilian fiction receives and processes the culture inflows of the most recent stages of capitalism, in which standardized images, connected to dynamics of consumption, are disseminated. Besides, particularistic statements, related to space, ethnicity and gender, among different identity marks of otherness, could emerge in this condition. Carolina Maria de Jesus stands out in the beginning of this scenario as an (ex)centric author, producing a writing which escapes from any essentialism and presents the hybridity mark. This article pretends to analyze her particular decentering as the resulting phenomenon of a creation process, conceptualized by Raffaella Fernandez (2015) as a "poetic of residues", which consists is a mixture of de-territorialized literary styles, often in conflict, becoming impossible to extract stable synthesis of Beyond all pity.
\end{abstract}

Keywords: Decentering. Hybridity. Poetic of residues. Beyond all pity.

\section{RESUMEN}

Insertada en el contexto de la globalización, la ficción brasileña contemporánea recibe y procesa los influjos de la cultura de esta etapa más reciente del capitalismo, en la cual se diseminan imágenes estandarizadas vinculadas a la dinámica del consumo y en la cual, dialécticamente, emergen afirmaciones particularistas en relación al espacio, etnia o género, entre otras marcas identitarias de alteridad. Carolina Maria de Jesus se destaca en los primordios de ese escenario como autora en todos eses aspectos (ex)céntrica, pero igualmente como productora de una escritura que escapa a cualesquier esencialismos, trayendo la marca del hibridismo. El artículo pretende analizar el descentramiento que le es peculiar como derivado de un proceso de creación conceptuado por Raffaella Fernandez (2015) como "poética de residuos", que consiste en la mezcla de estilos literarios deterritorializados, muchas veces en fricción y sin síntesis posible en el interior de Quarto de despejo: diário de uma favelada (Cuarto de despojo: diario de una barriobajera).

Palabras clave: Descentramiento. Hibridismo. Poética de resíduos. Quarto de despejo. 


\section{Introdução}

Etapa histórica complexa e ainda em andamento, a globalização estabelece sistemas de produção e transferências financeiras em escala mundial, incidindo nas mais diversas áreas da vida social. Às interações transnacionais passam a processar-se em ritmo extraordinário a partir dos anos 1970 nos âmbitos econômico, social, político e cultural, com dinâmicas próprias a cada um deles. Nessa nova etapa da divisão internacional do trabalho, informações e imagens da matriz norte-americana, centro hegemônico desse processo, passam a ser disseminadas pelos quatro cantos do planeta através dos meios de comunicação social, criando a paisagem do que Herbert McLuhan chamou "aldeia global" (1962).

Países periféricos como o Brasil recebem desde os anos 1950 o influxo de valores e bens culturais identificados com o universo simbólico norte-americano, dada a acentuada assimetria do poder transnacional entre o norte e o sul. Boaventura de Souza Santos interroga-se até que ponto a globalização acarreta homogeneização ou diversidade, uma vez que processos de hibridização resultam do embate entre ambas as tendências. A partir de Arjun Appadurai, o sociólogo português define que "a característica central da cultura global é hoje a política do esforço mútuo da mesmice e da diferença para se canibalizarem uma à outra e assim proclamarem o êxito do sequestro das duas ideias gêmeas do Iluminismo, o universal triunfante e o particular resistente" (APPADURAI, 2002 apud SANTOS, p. 46).

Carolina Maria de Jesus publica em 1960 Quarto de despejo: diário de uma favelada, narrativa hiperlocalizada, ancorada na realidade miserável de seu bairro, zona alagadiça e insalubre onde habitava a população miserável da cidade de São Paulo em plena era dos anos dourados de Juscelino Kubitchek. Se em seu tempo já se promovia a uniformização baseada no american way of life e anúncios publicitários nas revistas, filmes e programas de televisão criavam uma cena cultural desterritorializada, sua obra aponta no sentido oposto da reterritorialização, afirmada a partir de uma identidade local que rasurava a imagem de um país em avanço veloz rumo ao futuro, com o tão alardeado padrão triunfalista de desenvolvimento que lhe faria progredir "50 anos em 5".

A identidade de favelada não é reivindicada, mas denunciada em Quarto de despejo. A autora da favela não anuncia a emergência de uma demanda pelo direito às raízes como resistência local à homogeneização cultural que já se fazia presente em seu tempo na cena urbana mundial. Estando em um país periférico, marcado pela disparidade social, seja ela entre as classes sociais internas, entre as regiões geográficas do País, e finalmente entre ele próprio e a matriz desenvolvida, Carolina profere o seu discurso sobre a fome e a miséria a partir de uma situação marginal involuntária e desdenhada, de uma condição marginal inaceitável, porque fere direito humano básico à sobrevivência: "21 de maio de 1958: Eu ontem comi aquele macarrão do lixo com receio de morrer" (JESUS, 1997, p.40).

Ainda que Boaventura de Souza Santos defina que "se houver uma só, a resistência a ela [globalização] se dá pela localização auto-assumida" (2002, p. 72), a âncora lançada pela autora dos diários em território local não é de resistência ao universal triunfante, como já se afirmou, mas de testemunho de uma sobrevivente do massacre que foi para os segmentos desfavorecidos o processo histórico de construção nacional conduzido pelas elites brasileiras, cujos interesses impediam que se rompesse com a herança colonial da mentalidade escravista mantenedora de privilégios arcaicos e se fundasse uma República baseada no princípio moderno da cidadania:

13 de maio de 1958. Hoje amanheceu chovendo. É um dia simpático pra mim. É o dia da Abolição. Dia que comemora a libertação dos escravos.

[...] Choveu, esfriou. É o inverno que chega. E no inverno a gente come mais. A Vera começou pedir comida. E eu não tinha. Era a reprise do espetáculo. [...] Era 9 horas da noite quando comemos.

E assim no dia 13 de maio de 1958 eu lutava contra a escravatura atual - a fome! (JESUS, 2007, p. 31).

Carolina fala como representante dos escravos de sua época, aqueles que habitam a margem pauperizada de um país que está à margem do eixo dominante do poder na era global. Sua enunciação resulta de muitos deslocamentos, o da migrante que deixou a região da margem regional mineira em busca de melhores oportunidades na metrópole paulistana, o da mulher pobre do meio rural que conheceu de perto o modo de vida da classe média, trabalhando como empregada doméstica em casas de família na capital e, ainda, o da mulher descendente de africanos que sofreram a diáspora forçada no alvorecer da modernidade. Ela fala, portanto, de um local resultante de uma trajetória de vida marcada pela sobreposição de marginalidades variadas. A identidade forjada nesse processo que a levou a viver junto do lixo é uma identidade "marginal" não essencializada, uma identidade dinâmica e compósita, como a entende José Manuel Mendes:

As bases e as origens das identidades são os acidentes, as fricções, os erros, o caos, ou seja, o indivíduo forma sua identidade não da reprodução pelo idêntico oriunda da socialização familiar, do grupo de amigos, etc, mas sim do ruído social, dos conflitos entre os diferentes agentes e lugares de socialização (MENDES, 2002, p. 505). 
A construção identitária de Carolina é, desse modo, socialmente construída e reconstruída ao longo de sua vida por meio das diversas formas de interação social que vivenciou nesse percurso por diferentes espaços sociais e simbólicos. Canibalizam-se, assim, as referências e sua escrita traz as marcas dos diferentes sistemas culturais que foram compondo sua individualidade mutifacetada. Desta forma, até a mais notória marca identitária desta autora, a condição de moradora na favela do Canindé, apresenta-se trincada:

22 de junho de 1959: Era 6 horas quando apareceu um carro. Era um senhor que havia casado e veio dar-nos os sanduíches que sobrou. Eu ganhei alguns. Depois os favelados invadiram o carro. Os moços foram embora e disse que iam jogar os sanduíches no lixo que gente da favela são estúpidos e quadrúpedes que estão precisando de ferraduras (DE JESUS, 2007, p. 70-71).

A opinião depreciativa dos moços "de fora" sobre a "gente da favela" é incorporada e reiterada pela autora, embora ela ali resida. Ao longo das páginas de Quarto de despejo, a voz narrativa se descola de seu próprio meio e observa seus vizinhos com os olhos e os preconceitos dos habitantes do mundo "de fora" da favela:

24 de junho: Os favelados todos os anos fazem fogueiras. Mas em vez de arranjar lenha, rouba uns aos outros. Entram nos quintaes e carregam as madeiras de outros favelados [...] Não sei porque é que os favelados são tão nocivos (DE JESUS, 2007, p. 72).

Ou ainda: "25 de junho de 1959: [...] o favelado aprecia profundamente tudo que é pornográfico!” (DE JESUS, 2007, p. 72).

Cria-se, assim, na narrativa em foco uma entidade, "os favelados", e a população do espaço periférico passa a adquirir uma caracterização básica que é atribuída indiscriminadamente a todos os moradores do bairro, sendo entendida pela voz enunciadora como produto do meio deteriorado, em interpretação determinista ao estilo do Naturalismo novecentista. Os favelados são, desse modo, estigmatizados ao longo das páginas do diário como estúpidos, preguiçosos, cachaceiros, quadrúpedes, mesmo sendo a autora ela própria uma "favelada", alguém que mora na zona "enferma" (DE JESUS, 2007, p. 85) da cidade.

Contrariamente a essa focalização narrativa "de fora", narram-se também situações em que a protagonista afirma seu pertencimento ao entorno social, apontando as duras condições de vida que são comuns a todos "os favelados" e incluindo-se no conjunto através de um foco narrativo "de dentro" do ambiente inóspito: "22 de maio de 1958: Duro é o pão que nós comemos. Dura é a cama que dormimos. Dura é a vida do favelado" (DE JESUS, 2007, p.42). Nessas situações, sua voz se expressa por meio de um foco narrativo em terceira pessoa, exprimindo dramas coletivos que dizem respeito um "nós" marginalizado:

07 de junho de 1958: Nós somos pobres, viemos para as margens do rio. As margens do rio são os lugares do lixo e dos marginais. Gente da favela é considerado marginais. Não mais se vê os corvos voando as margens do rio, perto dos lixos. Os homens desempregados substituíram os corvos (JESUS, 2007, p. 55).

Boaventura de Souza Santos explica esse tipo de identidade cindida analisando a dinâmica da vida cultural contemporânea: "A diferença cultural subverte as ideias de unidade e uniformidade culturais na medida em que se afirma a partir de práticas enunciativas que são vorazes em relação aos diferentes universos culturais de que se servem" (2010, p. 237). Assim marcada pela alternância de pontos de vista quer externos quer internos, em uma composição heteróclita, a narrativa apresenta Carolina como uma individualidade em atrito consigo mesma, ora presumindo pertencer ao centro prestigiado, ora à periferia degradada, configurando em si mesma um "patchwork do cotidiano" (CERTEAU, 1998, p.46) de impensável arremate final.

Com o conjunto dos favelados ela compartilha não apenas a cama e a vida duras, pois a sobrevivência em região inóspita requer muita inventividade. Nos diários da favelada, descrevem-se gestos peculiares ao modo de estar no mundo das camadas populares, usualmente astutas na arte de enjambrar soluções para responder satisfatoriamente às necessidades da vida prática em meio a amplas carências. Isso se percebe no trecho de 22 de maio de 1958: "O barraco está cheio de pernilongos. Eu vou acender uma folha de jornal e passar pelas paredes. É assim que os favelados matam mosquitos" (DE JESUS, 2007, p. 85).

Representando desse modo as práticas inusitadas a que recorrem frequentemente os habitantes das margens do rio Tietê com vistas à dedetizar suas casas, a narradora rasura a imagem homogênea da cultura, pois se confunde com os demais marginais na solução acionada, porém deles se afasta ao ironizar o método. Em trechos como esse, Carolina oferece ao leitor uma amostragem da cultura da periferia como marcada pelo exotismo, sugerindo-a própria pertencer a um universo cultural mais sofisticado, estando apenas sujeita às práticas paliativas ancoradas na cultura popular em virtude de dificuldades financeiras.

No que diz respeito às formas de tratamento médico presentes em Quarto de despejo, são exibidos no cotidiano da família inúmeros meios de cura alternativos à medicina tradicional, os únicos disponíveis aos favelados. Em 16 de junho de 1955, por exemplo, Carolina registra: 
O José Carlos está melhor. Dei-lhe uma lavagem de alho e um chá de ortelã (sic). Eu zombei do remédio da mulher, mas fui obrigada a dar-lhe porque atualmente a gente se arranja como pode. Devido ao custo de vida, temos que voltar ao primitivismo (DE JESUS, 2007, p. 65).

Dentro dos diários, narram-se diversas circunstâncias como essa, nas quais a mãe de Vera Lúcia mostra-se uma pessoa instruída, adepta da mentalidade científica e moderna, mas confessa recorrer às crendices da gente do povo para obter a cura por mera falta de opção. Os resultados dessas práticas "primitivas" mostram-se, a seu ver, inócuos ou mesmo prejudiciais: "19 de junho de 1958: [...] A Vera ainda está doente. Ela disse-me que foi a lavagem que eu dei-lhe que fez mal (DE JESUS, 2007, p. 67). Ou ainda: " 21 de junho de 1958: Ela [Vera] estava coçando-se e com a pele toda irritada. Acho que foi o chá de alho que the dei. Jurei nunca mais dar-lhe remedios (sic) indicados por lavadeiras de hospitais" (DE JESUS, 2007, p. 68).

As recomendações das pessoas mais simples, as "lavadeiras" não são dignas de apreço, Carolina se condena por tê-las seguido. Essa apreciação, que reproduz ainda uma vez juízo de valor preconceituoso proveniente dos extratos dominantes da sociedade, é realizada por uma papeleira, uma mulher situada em posto ainda inferior ao de lavadeira na hierarquia social, mas portadora de uma visão de mundo por vezes muito afeita aos valores da classe dominante, como se viu. No dia 16 de junho de 1955, no entanto, ela mostra-se contrariamente bastante apegada às superstições da cultura popular: "Eu estava indisposta, resolvi benzer-me. Abri a boca duas vezes, certifiquei-me que estava com mau olhado" (DE JESUS, 2007, p. 12).

Nem exclusivamente norteada pelos preceitos da medicina, discurso proveniente do centro hegemônico, nem tampouco apenas motivada pela crença nas ervas e benzeduras da cultura popular, Carolina se move entre referências provenientes de sistemas culturais distintos. Para o estudioso da cultura contemporânea Stuart Hall, a forma híbrida resulta exatamente da "fusão entre diferentes tradições culturais" (HALL, 2006b, p.91). Tal é a dinâmica que preside o conjunto das cenas apresentadas nesta narrativa, nas quais fragmentos de concepções e valores provenientes do espaço periférico dialogam intimamente com outros tantos estilhaços do idioma dominante, absorvem-no e processam-no em formas híbridas, impedindo que centro e periferia sejam pensados como universos estanques.

O descentramento do universo simbólico de Carolina Maria de Jesus está presente em Quarto de despejo também no que diz respeito ao âmbito do lazer. Em 17 de julho de 1955, por exemplo, ela relata: "- Fiquei boa, graças a Deus. E até pude dançar no Carnaval, com minha fantasia de penas" (DE JESUS, 2007, p. 15). Festa maior da cultura popular nacional, o carnaval sabidamente encontra nas zonas marginais e periféricas (sobretudo nos "morros" cariocas), a base social mais evidente dos componentes que lhe fazem existir.

Ainda que refira nas páginas dos diários não beber e nem se agradar da música dos favelados, que avança pela madrugada atrapalhando o sono dos que acordam cedo para trabalhar, Carolina aprecia a festa e tem até fantasia. Por outro lado, conta em 23 de julho de 1955: "Liguei o rádio para ouvir o drama. [...] Dormi uma hora e meia. Nem ouvi o final da peça. Comecei a fazer o meu diário" (DE JESUS, 2007, p. 25). O mundo da favela não é um manancial de cultura popular, como afoitamente se poderia julgar. Há ali espaço para a ainda incipiente cultura de massas, representada na radionovela que a autora dos diários acompanha.

A cena cultural descrita nas páginas de Quarto de despejo mescla elementos provenientes do próprio espaço periférico com elementos da cultura de massa em fase de afirmação no País, confirmando a consideração de Stuart Hall segundo a qual "não existe uma 'cultura popular' autêntica e autônoma, situada fora do campo de força das relações de poder e dominação" (HALL, 2006, p. 237). $\mathrm{Na}$ cartografia da cultura de nossos tempos que os diários oferecem, "não existe um enclave isolado fora do circuito de distribuição do poder cultural e das relações de força cultural" (2006, p. 237).

O próprio fato de o carnaval, espetáculo de raiz popular baseado no samba, música gestada e propagada em solo brasileiro pelos segmentos afrodescendentes em ato de resistência cultural ao branqueamento implementado pelas autoridades desde os primórdios da República, ter se tornado posteriormente um produto cultural midiático, absorvido e consumido massivamente nos meios televisivos, comprova a impossibilidade de se pensar a cultura de nosso tempo em pavilhões estanques e incomunicáveis e fora das relações de poder e dominação. Isso é exatamente o que Néstor García Canclini, pensando a partir do espaço da América Latina, ressalta:

Assim como não funciona a oposição abrupta entre
o tradicional e o moderno, o culto, o popular e
o massivo, não estão onde estamos habituados a
encontrá-los. É necessário demolir esta divisão
em três pavimentos, essa concepção de camadas
do mundo da cultura, e averiguar se sua hibridação
pode ser lida com as ferramentas das disciplinas
que os estudam separadamente: a história da arte e
a literatura que se ocupam do "culto"; o folclore e a
antropologia, consagrados ao popular; os trabalhos
sobre comunicação, especializados na cultura massiva.
Precisamos de ciências sociais nômades, capazes de
circular pelas escadas que ligam esses pavimentos. Ou
melhor: que redesenhem esses planos e comuniquem
os níveis horizontalmente (CANCLINI, 1998, p. 19). 
Mesmo que situado no terreno dos estudos literários, o presente artigo acolhe com apreço a orientação feita pelo sociólogo argentino acerca da necessidade do "nomadismo" na investigação científica, uma vez que ela permite pensar como intrinsecamente ligadas as instâncias do culto, do popular e do massivo na cena cultural contemporânea. Tal combinação comparece precisamente nas páginas de Quarto de despejo, nas quais Carolina descreve sua vida cultural por meio não apenas da festa popular e da novela radiofônica, mas ainda e essencialmente por meio da leitura e do convívio com os livros.

Na prateleira rústica do barraco de madeiras podres situado nas labirínticas ruelas do Canindé encontram-se obras de poetas românticos, Castro Alves e Casemiro de Abreu, que ela cita: "19 de maio de 1958: [...] E eu pensei no Casemiro de Abreu, que disse: 'Ri criança. A vida é bela.' Só se a vida era boa naquele tempo. Porque agora a época está apropriada para dizer: "Chora criança. A vida é amarga" (DE JESUS, 2007, p. 37).

O universo cultural de Carolina compõe-se, no âmbito literário, das referências citadas da literatura brasileira e ainda de algumas fábulas da literatura ocidental, conforme registra: "1 de novembro de 1958: Ontem eu li a fábula da rã e da vaca. Tenho a impressão que sou rã. Queria crescer até ficar do tamanho da vaca" (DE JESUS, 2007, p. 125).

Com uma base cultural na qual a unidade e a uniformidade inexistem, cedendo lugar a formas culturais "contraditórias, compostas de elementos antagônicos e instáveis" (HALL, 2006, p.241) o que fundamenta a criação literária de Carolina? Ou, melhor formulando, como essa base de barreiras porosas entre os sistemas culturais específicos que consome se traduz em poética na sua escrita?

Diversos críticos vêm apontando, desde a publicação de Quarto de despejo: diário de uma favelada, (1960), a configuração descentrada de sua criação literária, formulando assim o que já constitui hoje uma vertente fecunda de análise do conjunto de sua produção. Tomando exclusivamente a obra de estreia como corpus de análise, pode ser referida inicialmente Marisa Lajolo, que em "A leitora do quarto dos fundos" apontou em Quarto de despejo sua "dilacerada mestiçagem textual onde convivem preciosismo e infração", "a hipercorreção e a hipoconcordância” (1995, p. 13), sendo a primeira crítica, salvo engano, a reconhecer a presença do hibridismo como traço central de sua forma:

Em Quarto de despejo, a protagonista não se lava, ablui-se (p. 9), o que desliza no espaço é o astro-rei e não o sol (p. 9), ela não acorda, desperta (p. 82); tais lantejoulas desafinavam; e no desafino tinham de haver-se com os avessos da imagem de modernidade informal, avesso pouco palatável quando o pólo de sua emissão era uma mulher negra e pobre, encarnação concreta, portanto, daqueles despossuídos de cuja imagem a literatura talvez quisesse aproximar-se, ao cotidianizar-se, popularizar-se, modernizar-se (LAJOLO, 1995, p. 13).

“As lantejoulas da linguagem" da autora da favela apontadas por Marisa Lajolo sintetizam a ideia da hibridação presente em seu texto, ao mesmo tempo precário e sofisticado, ancorado na realidade da favela e voltado ao centro da vida cultural onde estavam os leitores que Carolina com tanto empenho buscava, e igualmente os editores, que poderiam trazê-los a si. O ensaio de Lajolo é breve e não esgota a análise do aspecto híbrido da produção caroliniana, mas aponta um caminho analítico promissor.

Alfredo Bosi, em Literatura e resistência, refere de forma breve que Carolina Maria de Jesus se situaria dentro da literatura brasileira contemporânea como portadora do que chamou à época uma "cultura de fronteira" (BOSI, 2002), atentando para a presença do traço da oralidade como peculiar à escrita literária dos segmentos excluídos.

Muda a nomenclatura, mas considera-se idêntica feição multifacetada em sua escrita, no caso entre o registro oral e padrão culto.

Foi, no entanto, Raffaella Fernandez quem elaborou o conceito que abarca de um modo amplo e profundo o hibridismo inerente à escrita caroliniana. Tomando como corpus de análise o conjunto dos manuscritos do espólio de Carolina Maria de Jesus, e não a edição de Quarto de despejo realizada por Audálio Dantas em 1960, a pesquisadora definiu como uma "poética de resíduos" o processo criativo da autora. Presente já na dissertação de mestrado intitulada Carolina Maria de Jesus, uma poética de resíduos (2006) o conceito foi mais tarde retomado na tese Processo criativo nos manuscritos do espólio literário de Carolina Maria de Jesus (2015).

Buscando conhecer a totalidade do material deixado pela escritora para reconstituir o que seria a integridade de seu acervo, a estudiosa da Unicamp entende que a escrita de Carolina espelha a rotina do cotidiano de trabalho de uma mulher papeleira, que recicla os materiais que encontra pelo caminho. Diz Raffaella Fernandez: “O diário de uma favelada está montado sobre restos de discursos, assim como as habitações da favela são construídas com os restos da cidade. Nos escritos de Carolina de Jesus encontra-se uma forma análoga à de um barraco, que aglomera material-argumentos temporários, frasearquitetura imprecisa, sempre em mutação geográficodiscursiva" (FERNANDEZ, 2015, p. 16).

Dentre os discursos reciclados pela autora mineira encontram-se recursos do lirismo dos poetas românticos referidos por ela, anseios de preciosismo lexical recolhidos dos poetas parnasianos, mesclados com a 
linguagem das radionovelas e das fábulas, todos artefatos culturais consumidos por ela, como se viu. Diz Raffaella Fernandez: "Carolina de Jesus inventa a língua da fome, da escassez, do descarte, fazendo seu texto valer por si mesmo" (FERNANDEZ, 2015, p. 16). Criando uma escrita representativa da condição de marginalidade em sua própria forma, esta autora faz da linguagem espelho de seu mundo escasso de recursos e ao mesmo tempo aberto à exploração criativa do que se encontre pelo caminho.

Dentre os resíduos que compõem sua bricolagem narrativa encontram-se, segundo a estudiosa, discursos literários e não literários, em constante atrito e ressignificados mutuamente nesse embate criativo. Procurando aproximar-se da literatura hegemônica, Carolina tece retalhos de pensamentos, tendo por base a forma autobiográfica dos diários, nos quais arquiva a memória de seu cotidiano de precariedades. A concepção de literatura de que é portadora exige, no entanto, que formas rebuscadas compareçam no texto, pois seu entendimento de literariedade é arcaico, exigindo o recurso às "lantejoulas" referidas por Marisa Lajolo.

Raffaella Fernandez tece fio promissor para percorrer o labirinto caroliniano sem perder-se no amontoado de linguagens por ela acionados, reciclados e ressignificados. Os manuscritos de Carolina, segundo a estudiosa, revelam a indissociabilidade verificada entre escrita e vida. A leitura crítica presente em sua tese ilumina o fazer literário da escritora como uma urgência, pois nos diários encontram-se

a escritura como alimento. A escritura como vida, como a própria existência; não apenas como trajeto, mas sim como instauração de um lugar. Uma vidaescrita ou por escrito repleta de uma potência impessoal emaranhada de técnicas de si e de suas infindas variações (FERNANDEZ, 2015, p. 25).

\section{Considerações finais}

$\mathrm{O}$ agenciamento de fragmentos discursivos de todos os tipos no texto de Carolina Maria de Jesus revela inequívocos processos de reconstrução identitária. Quem era ela, no entanto, é uma questão impossível de ser respondida através da leitura de seus diários, pois não há uma ali uma Carolina, porém várias, e muito ruído resulta do embate de diferentes perfis de si mesma. A notícia de que a autora do Canindé refazia, a cada ano, a fantasia de carnaval com penas de galinha d'angola, segundo Raffaella Fernandez, "para contrapor às plumas e paetês das belas vedetes, que desfilavam com toda pompa nas famosas avenidas" $(2015$, p. 26) parece sintetizar com muita felicidade o que este artigo pretende apresentar acerca de sua escrita descentrada.
Em sua performance carnavalesca hibridizada, Carolina sucumbe ao fetiche das plumas das fantasias luxuosas das vedetes, mas realoca-as dentro de um padrão compatível à sua vida de favelada. Exibindo penas de galinha d'angola na fantasia, ela ao mesmo tempo legitima e desloca o padrão do mais forte, criando um equilíbrio simbólico mais ou menos temporário. Boaventura de Souza Santos entende que,

[...] ao subverter os essencialismos, a hibridez pode alterar as relações de poder entre os sentidos dominantes e os sentidos dominados. O espaço híbrido cria abertura pelo modo como descredibiliza as representações hegemônicas e, ao fazê-lo, desloca o antagonismo de tal modo que ele deixa de sustentar as polarizações puras que o constituem (BOAVENTURA, 2010, p. 236).

A fantasia de Carolina, reinventando o luxo dentro da miséria, exemplifica tal subversão dos essencialismos, desorganizando as relações de poder entre sentidos dominantes e dominados. Ela descredibiliza a representação hegemônica do Carnaval como festa promovida de acordo com os padrões da elite e, ao fazê-lo, desloca o antagonismo que opõe Carolina às estrelas de tal modo que este deixa de sustentar as polarizações puras da cultura popular e da cultura dominante que o constituem. A veste carnavalesca da autora da favela pode ser inserida, portanto, no que Stuart Hall chama "o jogo das relações culturais: a luta de classes na cultura" (2006, p. 242). Ela negocia com os dois sistemas simbólicos e não se deixa encaixar em nenhum deles. Nada mais típico de Carolina Maria de Jesus.

Sabe-se que "as identidades constroem-se no e pelo discurso, em lugares históricos e institucionais específicos, em formações prático-discursivas e por estratégias enunciativas precisas" (MENDES, 2002, p. 506). A construção identitária de Carolina se dá por meio de estratégias enunciativas de descentramento presentes ao longo das páginas de Quarto de despejo, para as quais confluem aspectos históricos e institucionais e das quais resulta uma imagem de mulher que não cabe em definição alguma porque resulta do cruzamento de todas elas em um processo que só termina quando a papeleira coloca o ponto final e encerra seu texto.

\section{Referências}

BOSI, Alfredo. Literatura e resistência. São Paulo: Cia das Letras, 2002.

CANCLINI, Néstor Garcia. Culturas híbridas: estratégias para entrar e sair da modernidade. Tradução de Ana Regina Lessa e Heloísa Pezza Cintrão. 2. ed. São Paulo: Edusp: 1998. 
DE CERTEAU, Michel. A invenção do cotidiano: artes de fazer. Trad. Ephrain F. Alves. 3. ed. Petrópolis: Vozes, 1998.

FERNANDEZ, Raffaella. Processo criativo no espólio literário de Carolina Maria de Jesus. Instituto de Estudos da Linguagem da Universidade Estadual de Campinas. Programa de Pós-Graduação em Teoria e História Literária, Campinas, 2015. https://doi.org/10.20396/ccfenf1201831

HALL, Stuart. Da diáspora: identidades e mediações culturais. Que negro é esse na cultura negra? Belo Horizonte: Editora UFMG, 2006. p. 317-330.

HALL, Stuart. Identidade cultural na pós-modernidade. Rio de Janeiro: DP\&A, 2006b.

JESUS, Maria Carolina de. Quarto de despejo. 9. ed. São Paulo: Ática, 2007.

DE CERTEAU, Michel. A invenção do cotidiano: artes de fazer. Trad. Ephrain F Alves. 3. ed. Petrópolis: Vozes, 1998.

LAJOLO, Marisa. A leitora do quarto dos fundos. Leitura: Teoria e prática, Campinas, Mercado Aberto, n. 25, p. 10-18, jun. 1995.

MCLUHAN, Herbert. A Galáxia de Gutenberg. São Paulo: Nacional, 1962.

MENDES, José Manuel. O desafio das identidades. In: SANTOS, Boaventura Souza de. A globalização e as ciências sociais. São Paulo: Cortez, 2002. p. 503-540.

SANTOS, Boaventura Souza de (org.). A globalização e as ciências sociais. São Paulo: Cortez, 2002.

SANTOS, Boaventura de Souza. A gramática do tempo: para uma nova cultura política. 3. ed. São Paulo: Cortez, 2010. (Coleção para um novo senso comum, v. 4). https://doi. org/10.7476/9788578791209.0005

\section{Autora:}

Luciana Paiva Coronel

Doutora. Professora na Universidade Federal do Rio Grande (FURG), Rio Grande, RS, Brasil.

Orcid: https://orcid.org/0000-0001-6230-1878

E-mail: lu.paiva.coronel@gmail.com

Endereço: Universidade Federal do Rio Grande

Av. Itália, s/n, km 8 - Carreiros

96203-000, Rio Grande, RS, Brasil 